\title{
DIAGNOSIS AND TREATMENT OF HYPERTENSIVE DISORDERS DURING PREGNANCY
}

\author{
I. G. Fabry' ${ }^{1}$, T. Richart ${ }^{2,3}$, X. Cheng ${ }^{2,3}$, L. M. Van Bortel' ${ }^{1}$, J. A. Staessen ${ }^{2,3}$ \\ ${ }^{1}$ Heymans Institute of Pharmacology, Department of Clinical Pharmacology, Ghent University Hospital, \\ Ghent, Belgium, ${ }^{2}$ Genetic Epidemiology Unit, Department of Epidemiology, Maastricht University, \\ Maastricht, The Netherlands and ${ }^{3}$ Studies Coordinating Centre, Division of Hypertension and \\ Cardiovascular Rehabilitation, Department of Cardiovascular Diseases, University of Leuven, \\ Leuven, Belgium
}

Correspondence and offprint requests to: Isabelle Fabry, E-mail: isabelle.fabry@ugent.be

\section{ABSTRACT}

Pregnancy is a cardiovascular and metabolic challenge to the human female body. This review summarizes current knowledge on the regulation of blood pressure and plasma volume in normal and hypertensive pregnant women. During pregnancy, systemic vascular resistance and blood pressure decrease, whereas cardiac output and blood volume increase to safeguard an adequate circulation in the utero-placental arterial bed. Hypertension affects $10 \%$ of all pregnancies and is accompanied by an increase in foetal and maternal morbidity and mortality. Hypertension in pregnancy includes a wide spectrum of conditions, including pre-eclampsia and eclampsia, pre-eclampsia superimposed on chronic hypertension, chronic hypertension, and gestational hypertension. Endothelial dysfunction, oxidative stress and an exaggerated inflammatory response are features related to hypertensive disorders. Microangiopathic disorders can easily mimic hypertensive disorders during pregnancy. Although they have some symptoms in common, they require another type of management.

To reduce the risk of maternal and foetal complications due to haemodynamic maladaptations, the current management includes rest at home or in the hospital, close monitoring of maternal and foetal signs and symptoms, early start of antihypertensive therapy, and timely delivery regarding maternal and foetal survival chances. Thresholds to initiate blood pressure lowering treatment during pregnancy are $160 \mathrm{mmHg}$ systole or $110 \mathrm{mmHg}$ diastole. Below these thresholds, treatment must be individualized because current evidence does not support aggressive medical interventions. Alpha-methyldopa and dihydropyridinic calcium channel blockers are among the recommended antihypertensives.

Key words: hypertension, pregnancy, haemodynamics

\section{INTRODUCTION}

During pregnancy, haemodynamic and metabolic adaptations ensure adequate perfusion and nutrient delivery to the foetus. Hypertensive disorders complicate 1 out of 10 pregnancies, entailing an increased risk for maternal and foetal morbidity and mortality. Identification of risk factors, an early diagnosis of elevated blood pressure and subsequent antihypertensive treatment are of paramount importance. Although descriptions of haemodynamic changes during the course of pregnancy are plentiful, evidence-based guidelines for the treatment of hypertensive disorders during pregnancy are sparse. In this review, we summarize the mechanisms of blood pressure control and plasma volume regulation in normotensive and hy- 
pertensive pregnant women. In addition, we reviewed current recommendations for the diagnosis and treatment of hypertension during pregnancy.

\section{METHODS}

We searched for relevant publications in Medline, using the search terms: "plasma volume" AND "pregnancy", "blood pressure" AND "pregnancy", "pre-eclampsia", or "hypertensive disorders" AND "pregnancy". This resulted in relevant publications. We went through the reference lists of retrieved articles to identify relevant articles, which were not identified by the electronic search. In addition, the World Health Organisation (WHO) website was consulted to have actual data on the incidence and recent guidelines on the management of cardiovascular disorders during pregnancy. We focused mainly on randomized clinical trials and reviews in core clinical journals, which addressed the haemodynamic changes during pregnancy and the early postpartum. We discarded articles which focused on late pregnancy.
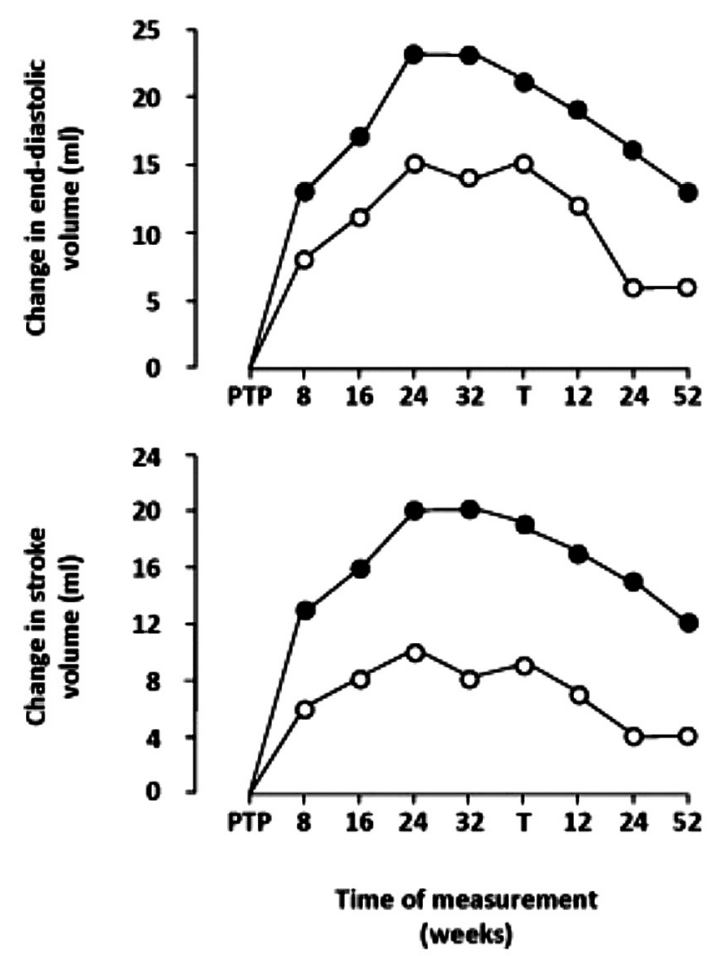

\section{HAEMODYNAMIC AND ENDOCRINE ADAPTATIONS TO PREGNANCY}

\section{Haemodynamic changes}

Profound cardiovascular adaptations start in the late luteal phase of the menstrual cycle (see Table 1).

Table 1: Summary of the important haemodynamic changes during pregnancy

\begin{tabular}{ll}
\hline Increased & Decreased \\
\hline Uterine blood flow & Systemic vascular resistance \\
\hline Plasma volume & Pulmonary vascular resistance \\
\hline Red blood cell mass & Hematocrit \\
\hline Cardiac diastolic dimension & Colloid osmotic pressure \\
\hline Stroke volume & Plasma albumin concentration \\
\hline Heart rate & Arterial carbon dioxide tension \\
\hline Arterial oxygen consumption & Arterial hydrogen ion concentration \\
\hline Venous capacitance & Arterial blood pressure \\
\hline
\end{tabular}

These haemodynamic alterations peak in the second trimester of pregnancy and return to non-pregnant levels near term $(1,2)$. They disappear within the first days after delivery, although abnormalities in volume homeostasis may persist for up to a year, called the protracted effect of pregnancy on the volume status (3) (see Figure 1).
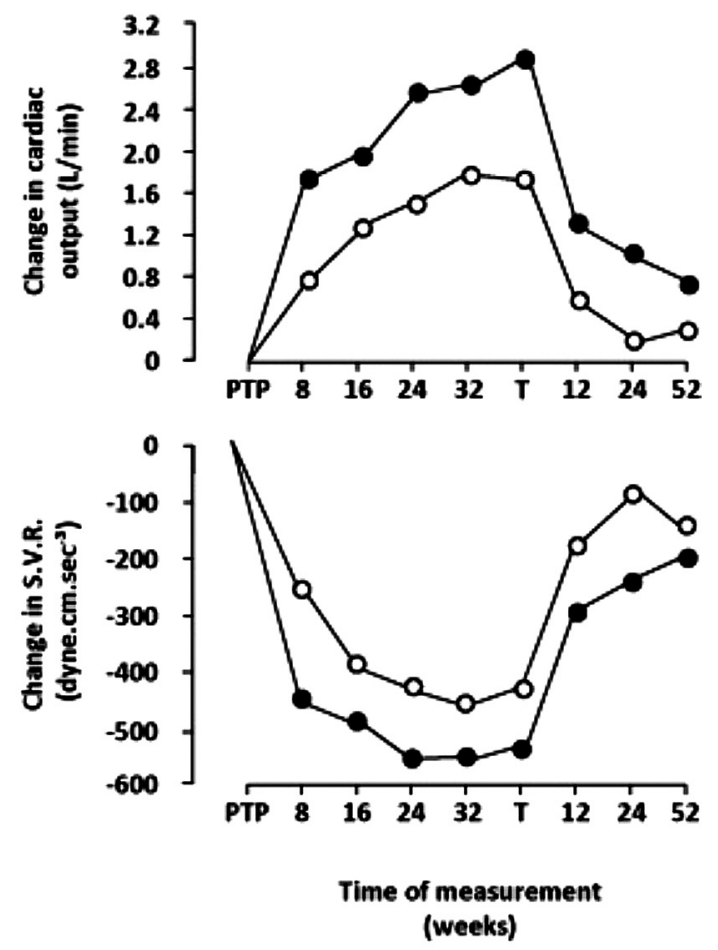

Figure 1: Haemodynamic adaptations before, during and after pregnancy PTP: pre-pregnancy time point, T: term, S.V.R.: systemic vascular resistance

Course of cardiac end-diastolic volume, stroke volume, cardiac output and systemic vascular resistance before and throughout pregnancy until 52 weeks postpartum. Open circles: data from 15 nulliparae; blinded circles: data from 15 parous women. Figure adapted from (52) 
The changes in the maternal haemodynamics in early pregnancy involve hormones that induce vasodilatation of the arterial and venous vasculature (4). These endocrine triggers already arise in the late luteal phase and cause a generalized fall in systemic vascular tone. Lower vascular resistance is one of the earliest maternal adjustments to pregnancy (5). Decreased vascular responsiveness to angiontensin II and norepinephrine and increased endothelial production of prostacyclin and nitric oxide (NO) may play a role as exemplified by the increased urinary excretion of kallikreine, cyclic guanosine monophosphate (cGMPsecond messenger of NO) and prostacyclins $(6,7)$. The subsequent rise in vascular capacitance creates a state of relative underfilling and initiates the cardiovascular adaptation to pregnancy (8-11).

The sensors perceiving and controlling intravascular volume are reset during normal pregnancy, enabling the maternal circulation to accommodate a gradual expanding plasma volume (to $40 \%$ at term) without provoking a natriuretic response (7). Meanwhile, red blood cell mass increases by $30 \%$, which is less than the expansion of the plasma volume. This explains to the so-called pregnancy-anaemia. The plasma protein concentration and plasma osmolality likewise decrease during pregnancy (12).

Afterload reduction activates baroreceptors. As a consequence heart rate, stroke volume and cardiac contractility increase and venous blood shifts towards the arterial compartment $(1,5,13)$. To meet the higher basal oxygen consumption in pregnant women (up to $50 \mathrm{~mL} / \mathrm{min}$ at term), cardiac output increases (12).

Systolic and diastolic blood pressures drop slightly during normal pregnancy as does pulse pressure with the maximum change found in the second trimester. When measuring blood pressure in pregnant women one should always account of posture, because in the supine position the pregnant uterus compresses the inferior caval vein, thereby reducing venous return and cardiac output $(1,12)$.

\section{Endocrine changes}

The secretion of adrenal steroids (aldosterone and cortisol) is elevated during pregnancy (to three times the non-pregnant levels) (14). Volume retention and restoration of the preload is due to activation of the renin-angiotensin-aldosteron system (RAAS) and stimulation of the secretion of cortisol and antidiuretic hormone $(\mathrm{ADH})(8,11,15,16)$. A concomitant decrease of atrial stretch suppresses the release of atrial natriuretic peptide (ANP) (17).

The endocrine adaptations induce water and salt retention, so that at the end of pregnancy 6-8 l of extra water are distributed among the foetus, the amniotic fluid and all the intra-and extracellular tissues of the mother (18).

In summary, the normal pregnancy is characterized by a generalized reduction of systemic vascular resistance and blood pressure and an increase in cardiac output and blood volume to ensure an adequate utero-placental circulation and increased blood flow to the breast and kidneys of the mother (12).

\section{DIAGNOSIS OF HYPERTENSIVE DISORDERS DURING PREGNANCY}

\section{Guidelines}

Hypertension affects $10 \%$ of all pregnancies $(19 ; 20)$. Therefore, blood pressure should be measured regularly in pregnant women. The guidelines of the American College of Obstetricians and Gynaecologists identify two subgroups: mild (140-159/90-110 mmHg) and severe (>160/110 $\mathrm{mmHg}$ ) hypertension $(20,21)$. The diagnosis of an elevated blood pressure and the differential diagnosis of hypertensive disorders during pregnancy are not easy. Hypertension in pregnancy is defined as two recordings of a blood pressure of at least $140 / 90 \mathrm{mmHg}$ at two occasions, separated by an interval of at least 6 hours. According to the Seventh Report of the Joint National Committee on Prevention, Detection, Evaluation and Treatment of High Blood Pressure, women with a systolic blood pressure of $120-139 \mathrm{mmHg}$ and/or a diastolic blood pressure of 80-89 mmHg should be considered as pre-hypertensive (22). The European Society of Hypertension recommends a threshold of $\geq 140 \mathrm{mmHg}$ systolic and/ or $\geq 90 \mathrm{mmHg}$ diastolic on repeated measurements (23). Nevertheless, the threshold of $140 / 90 \mathrm{mmHg}$ might be too high for young subjects, such as women of childbearing age. Thus, based on this threshold, the prevalence of hypertensive disorders during pregnancy might be underestimated (19).

\section{Risk factors}

Women with severe hypertension prior to pregnancy, hypertension in the first trimester despite use of antihypertensive medications, or both and those with 
adverse outcomes in a previous pregnancy are at very high risk of superimposed pre-eclampsia (50\%-75\%), foetal growth retardation (25\%-40\%), and abruptio placentae (10\%-20\%). Chronic hypertension tends to be more prevalent in Black women, women with obesitas or diabetes and older (>35 years) women $(20,24,25)$. Smoking enhances the risk and severity of adverse pregnancy outcomes, such as gestational hypertension. However recent epidemiologic data suggest that the risk of pre-eclampsia is decreased by $30 \%$ among young smokers without pregestational hypertension (26).

\section{Possible diagnoses}

This section describes the most common hypertensive disorders during pregnancy. Abnormal placentation is thought to be the cornerstone in the process of aberrant maternal-foetal interaction and placental hypoperfusion. Neurohormonal feedback induces or exacerbates maternal hypertension in an attempt to maintain placental perfusion and foetal growth (19).

\section{Chronic hypertension}

Chronic hypertension, present before pregnancy or before 20 weeks of gestation, complicates approximately $3 \%$ of all pregnancies. Essential hypertension is the most common cause (20). When blood pressure decreases during mid-pregnancy, the blood pressure tends to become "normal". At the end of pregnancy, when blood pressure returns to pregravid levels, women with pre-existing chronic hypertension might be diagnosed as hypertensive for the first time. When blood pressure fails to normalize after delivery (longer than 12 weeks postpartum), the diagnosis of chronic hypertension can only be made retrospectively (19).

Therefore, women should be evaluated prior to conception to define their blood pressure status, and, if hypertensive, to assess the severity, possibly remediable causes, and the presence of target organ damage. As a general rule, women have a lower blood pressure than men, but with the increasing prevalence of obesity and the metabolic syndrome a growing proportion of women present with hypertension at younger age (22). Up to $30 \%$ of women with chronic hypertension develop pre-eclampsia.

\section{Gestational hypertension}

Gestational hypertension is hypertension occurring for the first time during the second half of pregnancy in the absence of proteinuria. It occurs in $6 \%$ of all pregnancies. Women with gestational hypertension progress to pre-eclampsia in $15 \%$ to $45 \%$ of cases $(19,20,22,27)$

These patients should be monitored very closely to determine whether pre-eclampsia or other causes of gestational hypertension exist. Early delivery and foetal monitoring are sometimes needed because gestational hypertension, when severe, may lead to higher rates of premature delivery and growth retardation than mild pre-eclampsia. When blood pressure remains elevated after delivery, the diagnosis of chronic hypertension should be kept in mind. It is very important to differentiate pre-eclampsia, a pregnancy-specific syndrome from pre-existing chronic hypertension or gestational hypertension.

\section{Pre-eclampsia / Eclampsia}

In addition to an elevated blood pressure, the diagnosis of pre-eclampsia rests on the appearance of proteinuria in the third trimester of pregnancy in women without proteinuria before pregnancy (28). Pre-eclampsia occurs in $3-5 \%$ of pregnancies $(19,20)$ and is characterized by hypertension and proteinuria of $300 \mathrm{mg}$ or greater in a 24-hour urine sample. The convulsive form of pre-eclampsia, eclampsia, affects $0.1 \%$ of all pregnancies $(19,20)$. Pre-eclampsia and eclampsia are responsible for $12 \%$ of the global maternal deaths (28). The syndrome is more common in nulliparous women, in multiple gestation, in women with a history of gravid or non-gravid hypertension or renal disease or in women with a positive family history of pre-eclampsia in a first degree relative (22).

The haemodynamic changes and adaptations during pregnancy might unmask underlying endothelial dysfunction, leading to clinical syndromes as pre-eclampsia and eclampsia that resolve with termination of pregnancy. The disease is characterized by systemic vasoconstriction and reduced plasma volume, leading to systemic ischaemia, which is the substrate for hypertension and multi-organ dysfunction. Preeclamptic patients might be at higher risk of developing cardiovascular diseases later in life $(29,30)$. They have approximately a 2-to 3-fold higher risk in developing early cardiac, cerebrovascular, and peripheral arterial disease, and cardiovascular mortality(31-35). Similarities exist between the metabolic abnormalities that are associated with increased risk for cardiovascular diseases and pre-eclampsia. These include insulin resistance, obesity and lipid abnormalities. In pre-eclampsia, as in atherosclerosis, oxidative stress resulting from free radicals contributes to endothelial dys- 
function. Evidence for this feature includes increased lipid peroxidation, diminished activity of antioxidant enzymes and an increased capacity of the placenta to generate reactive oxygen species $(36,37)$.

An inflammatory response is one of the adaptations that occur during normal pregnancy. It probably reflects an immune reaction of the maternal body to foetal antigens. This inflammatory response may be exaggerated in pre-eclampsia as exemplified by the higher neutrophil activation compared with normal pregnancies (reflected by higher levels of neutrophil elastase, VCAM-1 (vascular cell adhesion molecule-1), ICAM-1 (inter-cellular adhesion molecule-1), TNF (tumour necrosis factor) and IL-6 (interleukine-6)). A high CRP (C-reactive protein)-level in pre-eclampsia illustrates the continuum between hypertensive disorders during pregnancy and cardiovascular diseases later in life (38-40).

\section{HELLP-syndrome}

Haemolysis $(\mathrm{H})$ combined with a micro-angiopathic blood smear, increased liver enzymes (EL), and low platelets (LP) in pregnancy was first described in 1982 and affects six in 1000 pregnancies (41). 5-10\% of women with pre-eclampsia develop HELLP (42). Risk factors to develop HELLP-syndrome include advanced maternal age, multiparity and white ethnic origin(43). The neonatal mortality rate can be very high (6-70\%) due to premature delivery or maternal complications.

Very often, the patient gets a non-obstetric diagnosis, which leads to an inadequate treatment. HELLP patients often report right upper quadrant pain, nausea and vomiting. Hypertension and proteinuria are present in $85 \%$ of the cases. HELLP starts usually in the second or third trimester, but can also develop in the near postpartum without any sign or symptom of pre-eclampsia. The patients need aggressive therapy to prevent maternal and neonatal mortality.

\section{Differential diagnoses}

Pregnant women developing severe symptoms suggestive of pre-eclampsia before 30 weeks should be tested for autoimmune disorders or acquired trombophilias.

\section{Acute fatty liver of pregnancy}

Acute fatty liver of pregnancy affects approximately 1 of 10000 pregnancies and presents in late pregnancy ( $27-40$ weeks). It is caused by a recessive inherited defect in foetal long chain 3-hydroxyacyl- coenzyme A hydrogenase. This mutation causes mitochondrial dysfunction with accumulation of fatty acid metabolites. The mother presents with progressive fatigue, malaise, anorexia, nausea, vomiting and mid-epigastric or right upper quadrant pain and jaundice. Hepatic dysfunction leads to mental changes, hypertension, proteinuria, severe hyperglycaemia and coagulopathy. The fatty infiltration of the liver may be diagnosed by ultrasound, CT or MRI imaging of the abdomen. However, the diagnostic standard is liver biopsy, but this is rarely done in practice due to procedural risk. Billirubin levels are typically higher (5-10 mg/dL) than seen in pre-eclampsia (2-3 mg/dL). Recent data indicate maternal perinatal mortality rates of approximately $10 \%$ (20).

\section{Thrombotic microangiopathies}

Thrombotic thrombocytopenic purpura (TTP) and haemolytic uremic syndrome (HUS) are extremely rare during pregnancy and the postpartum period ( $<1$ case in 100000 pregnancies), but have a very dire outcome. Maternal survival improved from $40 \%$ to $90-100 \%$. However, the maternal morbidities continue to be high. The foetal and neonatal mortality can be as high as $40 \%$. The classic pentad of TTP and HUS (thrombocytopenia, microangiopathic haemolytic anaemia, neurologic abnormalities, fever and renal dysfunction) has significant clinical overlap with eclampsia. Symptoms of eclampsia before 20 weeks of gestation might herald TTP/HUS $(20,44)$.

\section{Systemic Lupus Erythematosus (SLE)}

SLE is an auto-immune disorder occurring frequently in women in their childbearing years with diverse clinical findings, which can be mild or severe and may include multiple organ systems (kidneys, lungs, liver and brain) $(20,45)$. It may develop for the first time during pregnancy or in the postpartum period. In patients with lupus nephritis, the clinical and laboratory findings are similar to those of severe preeclampsia (hypertension, proteinuria and microscopic haematuria). Most patients in the acute phase have skin and joint lesions. APAs (lupus anticoagulant and/ or anticardiolipin antibodies) are present in $30-40 \%$ of women with SLE. These patients are at increased risk for thrombotic events with tissue ischaemia secondary to an event. The clinical picture then becomes very similar to that of the HELLP syndrome, eclampsia, TTP and HUS. Maternal morbidity and mortality are high in those with renal and central nervous system involvement and in those with antiphospholipid (APA) syn- 
drome. Maternal mortality is almost $50 \%$ in patients who develop catastrophic APA syndrome due to acute thrombotic microangiopathy. Because of placental infarctions or haemorrhage, foetal and neonatal morbidity and mortality is very high (foetal death in $4-19 \%$ and preterm delivery in $38-54 \%$ of the cases) (46).

\section{TREATMENT OF HYPERTENSIVE DISORDERS DURING PREGNANCY}

\section{Guidelines and goals}

The treatment of severe hypertension (SBP> 160 $\mathrm{mm} \mathrm{Hg}, \mathrm{DBP}>110 \mathrm{mmHg}$ ) has the primary goal to reduce the risk of severe maternal morbidity (cerebral haemorrhage, liver rupture, renal insufficiency and abruptio placentae) and foetal morbidity (preterm birth). There is little evidence to support aggressive medical interventions for levels of blood pressures below 160 $\mathrm{mmHg}$ systolic or $110 \mathrm{mmHg}$ diastolic. In such patients, the decision to treat hypertension must be individualized (21)According to a recent Cochrane review (47), recommended antihypertensive medications are all better than placebo. They are useful and effective in preventing haemodynamic complications and progression to severe hypertension. There are, unfortunately, insufficient data to firmly recommend at which level of blood pressure antihypertensive drug treatment should be started. Whether or not the appearance of proteinuria justifies lower thresholds to initiate antihypertensive treatment also remains to be elucidated.

The safety of the mother must come first and one should consider early delivery of the foetus. Immediate goals of therapy in severe hypertension during pregnancy are a $25 \%$ reduction of mean arterial pressure (MAP) within 2 hours of the clinical presentation and a goal below 160/110 mmHg in the next hours. Abrupt reductions of MAP by more than $25 \%$ might lead to end-organ hypo-perfusion or foetal injury due to placental infarction (27).

The current management of pre-eclampsia includes close monitoring of maternal and foetal signs and symptoms, rest at home or in the hospital, antihypertensive drugs to control hypertension, and timely delivery (according to gestational age, disease severity, and results of maternal-foetal monitoring). Several groups of antihypertensive medications are frequently used. Clinicians should make an educated choice based on already known effects on maternal and foetal morbidity of the particular drug (see Table 2 and 3).
Table 2: Food and DrugAdministration (FDA) categorization of drug risks to the foetus.

\begin{tabular}{|c|}
\hline FDA categorization \\
\hline Category A \\
\hline $\begin{array}{l}\text { Controlled studies in women fail to demonstrate a risk to the fetus } \\
\text { in the first trimester (and there is no evidence of a risk in later } \\
\text { trimesters), and the possibility of fetal harm appears remote. }\end{array}$ \\
\hline Category B \\
\hline $\begin{array}{l}\text { Either animal-reproduction studies have not demonstrated a fe- } \\
\text { tal risk but there are no controlled studies in pregnant women, or } \\
\text { animal-reproduction studies have shown an adverse effect (other } \\
\text { than a decrease in fertility) that was not confirmed in controlled } \\
\text { studies in women in the first trimester (and there is no evidence } \\
\text { of a risk in later trimesters). }\end{array}$ \\
\hline Category C \\
\hline $\begin{array}{l}\text { Either studies in animals have revealed adverse effects on the fe- } \\
\text { tus (teratogenic or embryocidal or other) and there are no con- } \\
\text { trolled studies in women, or studies in women and animals are } \\
\text { not available. Drugs should be given only if the potential benefit } \\
\text { justifies the potential risk to the fetus. }\end{array}$ \\
\hline Category D \\
\hline $\begin{array}{l}\text { There is positive evidence of human fetal risk, but the benefits } \\
\text { from use in pregnant women may be acceptable despite the risk } \\
\text { (e.g., if the drug is needed in a life-threatening situation or for a } \\
\text { serious disease for which safer drugs cannot be used or are inef- } \\
\text { fective). }\end{array}$ \\
\hline Category X \\
\hline $\begin{array}{l}\text { Studies in animals or human beings have demonstrated fetal ab- } \\
\text { normalities, or there is evidence of fetal risk based on human ex- } \\
\text { perience or both, and the risk of the use of the drug in pregnant } \\
\text { women clearly outweighs any possible benefit. The drug is contra- } \\
\text { indicated in women who are or may become pregnant. }\end{array}$ \\
\hline
\end{tabular}

\section{First choice antihypertensive drugs \\ Methyldopa}

Alpha-methyldopa does not reduce the uteroplacental blood flow and hence has no effect on the foetal growth. This drug has been used extensively in obstetrics for years and has been considered useful as a maintenance therapy to gradually lower the blood pressure. It is one of the Food and Drug Administration class B medication for hypertension $(20,48)$. Known side effects are mostly minor like postural hypotension, dizziness and liver function disorders.

\section{Calcium channel blockers}

Calcium channel blockers are safe molecules (see Table 3). No adverse neonatal events have been registered until today (49). The more commonly used drug is nifedipine. It exists in fast and slow release preparations. The preference goes to the slow release form in order to prevent sudden onset of maternal hypotension and reflex tachycardia with foetal distress consequently. Because of the increased renal and hepatic clearance related to pregnancy, starting doses and administration frequency often require adjustments (48). 
Table 3: Summary of antihypertensive drugs.

ACE: angiotensin converting enzyme, ARB: angiotensin receptor blocker, $\mathrm{HT}$ : hypertension, IU: intrauterine, CV: cardiovascular, I.V.: intravenously

\begin{tabular}{|c|c|c|c|c|}
\hline Drugs & & Indication & Fetal Risk & Breast Feeding \\
\hline \multicolumn{5}{|l|}{ Beta-blockers } \\
\hline Acebutolol & B & $\mathrm{HT}$, ventricular arrythmias & $\begin{array}{l}\text { Crosses placenta. No reports of IU growth retardation, } \\
\beta \text {-blockade near term }\end{array}$ & Secreted into milk, not recommended \\
\hline Atenolol & $\mathrm{D}$ & HT & $\begin{array}{l}\text { Crosses placenta. Toxic at high doses. IU growth retardation } \\
\beta \text {-blockade near term }\end{array}$ & Secreted into milk, not recommended \\
\hline Betaxol & C & HT, glaucoma & Teratogenic in animals, $\beta$-blockade near term & Secreted into milk, no data available \\
\hline Bisoprolol & C & HT & Fetotoxic in animals, $\beta$-blockade near term & $\begin{array}{l}\text { Secreted into milk in animals, no data } \\
\text { available }\end{array}$ \\
\hline Carvedilol & $\mathrm{C}$ & $\mathrm{HT}$, angina & Fetotoxic in animals, no well controlled human data & Secreted into milk, not recommended \\
\hline Labetalol & C & HT, sympathicolysis & $\begin{array}{l}\text { Crosses placenta, IU growth retardation, } \\
\text { induction of fetal lung maturation near term }\end{array}$ & Secreted into milk, safe under observation \\
\hline Metoprolol & C & HT, sympathicolysis & $\begin{array}{l}\text { Crosses placenta. Fetotoxic in animals. IU growth retardation, } \\
\text { neonatal } \beta \text {-blockade }\end{array}$ & Compatible, safe with neonatal observation \\
\hline Nebivolol & C & HT & Not recommended & Secreted into milk, not recommended \\
\hline Pindolol & B & HT & $\begin{array}{l}\text { Crosses placenta, no anomalies. IU growth retardation, } \\
\text { neonatal } \beta \text {-blockade }\end{array}$ & Compatible, safe with neonatal observation \\
\hline Propranolol & $\mathrm{C}$ & HT, hyperthyroidism, tachycardia & Embryotoxic in animals, not recommended in humans & Compatible, safe with neonatal observation \\
\hline \multicolumn{5}{|c|}{ Calcium Channel Blockers } \\
\hline Verapamil & C & $\mathrm{HT}$, antiarrhythmic & $\begin{array}{l}\text { Embryotoxic in animals, } \\
\text { maternal hypotension with fetal hypoxia when given I.V. }\end{array}$ & Nursing should be discontinued \\
\hline \multicolumn{5}{|c|}{ Dihydropyridines } \\
\hline Amlodipine & $\mathrm{C}$ & HT & Prolongs labor in animals, no human data & No data available \\
\hline Felodipine & $\mathrm{C}$ & HT & Teratogenic in animals, no adequate human data & Unknown excretion \\
\hline Nifedipine & C & $\mathrm{HT}$, vasospastic angina & $\begin{array}{l}\text { Teratogenic in animals, CV defects in 1st trimester, growth } \\
\text { retardation }\end{array}$ & Compatible, safe under observation \\
\hline Diltiazem & C & $H T$, angina & Teratogenic in animals, CV defects in 1st trimester & Compatible, safe under observation \\
\hline \multicolumn{5}{|l|}{ ACE inhibitors } \\
\hline & $D^{*}$ & HT & $\begin{array}{l}\text { Teratogenic in animals and humans from } 2 \text { nd trimester } \\
\text { no human data from 1st trimester }\end{array}$ & $\begin{array}{l}\text { No significant excretion into milk, } \\
\text { compatible }\end{array}$ \\
\hline \multicolumn{5}{|l|}{ ARB } \\
\hline & $D^{*}$ & HT & $\begin{array}{l}\text { Teratogenic in animals and humans from } 2 \text { nd trimester } \\
\text { no human data from 1st trimester }\end{array}$ & Not recommended during breastfeeding \\
\hline \multicolumn{5}{|c|}{ Alpha-blockers } \\
\hline Prazosine & $?$ & HT, Raynaud syndrome & Not recommended & Not recommended during breastfeeding \\
\hline \multicolumn{5}{|c|}{ Central antihypertensives } \\
\hline Clonidine & C & HT & Limited human data with CV defects & Not recommended during breastfeeding \\
\hline Guanfacine & B & HT & Limited human data; no adverse effects in animals & No data available \\
\hline Methyldopa & B & HT & Limited human data; no adverse effects in animals & $\begin{array}{l}\text { No significant excretion into milk, } \\
\text { compatible }\end{array}$ \\
\hline Moxonidine & $?$ & HT & Not recommended & Not recommended during breastfeeding \\
\hline \multicolumn{5}{|l|}{ Diuretics } \\
\hline \multicolumn{5}{|l|}{ lisdiuretics } \\
\hline Bumetanide & C & HT & Not teratogenic in animals, CV defects in 1st trimester in humans & Supresses lactation, not recommended \\
\hline Furosemide & $\mathrm{C}$ & $\mathrm{HT}$, congestive heart failure & Crosses placenta. Hypospadias in 1st trimester in humans & No data available \\
\hline \multicolumn{5}{|l|}{ Vasodilators } \\
\hline Hydralazine & C & HT & Crosses placenta, maternal and foetal lupus-like syndrome & Excreted into milk, safe in breastfeeding \\
\hline
\end{tabular}




\section{Second-line antihypertensive drugs Beta-blockers}

The use of this group may lead to intra-uterine growth retardation. However the evidence is based on a small placebo-controlled trial with atenolol (50). Labetalol ( $\alpha$-and $\beta$-receptor antagonist) is more safe and can be used both orally and intravenously. It gives a gradual decrease of the blood pressure without hypoperfusion of the utero-placental vasculature. High intravenous dosages shortly before delivery may cause therapy-resistant neonatal hypotension and bradycardia. Although labetalol has a long history of safety, some studies have associated it with foetal growth retardation.

\section{Hydralazine}

Hydralazine is a potent vasodilator and can be given intravenously or intramuscularly in hypertensive emergencies. The blood pressure lowering effect cannot always be controlled which sometimes lead to maternal hypotension and foetal distress $(20,27)$.

\section{Absolutely contra-indicated antihypertensive drugs ACE-inhibitors and $A R B S$}

ACE-inhibitors and ARBs are generally considered unsafe for the foetus and contraindicated for the whole course of pregnancy (48). These classes should also not be prescribed to women intending to become pregnant. They introduce foetal renal insufficiency with oligohydramnios and secondary effects like pulmonal hypoplasia, intrauterine growth retardation, dysmorphia and even foetal death (51).

\section{CONCLUSION - DISCUSSION}

Hypertensive disorders occur in $10 \%$ of pregnancies, and entail an increased risk for foetal and maternal morbidity and mortality throughout pregnancy and the post-partum period. Current guidelines support pharmacologic interventions in patients with SBP $>160 \mathrm{~mm} \mathrm{Hg}$ and/or DBP >110 mm Hg. Risk assessment, early diagnosis and adequate treatment of elevated blood pressure during pregnancy reduces morbidity and mortality in both mothers and infants.

\section{ACKNOWLEDGMENTS}

The authors gratefully acknowledge the expert assistance of Sandra Covens and Ya Zhu (Studies Coordinating Centre, Leuven, Belgium).

\section{REFERENCES}

1. Duvekot JJ, Peeters LL. Maternal cardiovascular hemodynamic adaptation to pregnancy. Obstet Gynecol Surv 1994; 49(12 Suppl): S1-14.

2. Voss A, Malberg H, Schumann A, Wessel N, Walther T, Stepan H, Faber R. Baroreflex sensitivity, heart rate, and blood pressure variability in normal pregnancy. Am J Hypertens 2000;1 3(11): 1218-25.

3. Finn WL, Tunny TJ, Klemm SA, Jones IS, De VK, Gordon RD. Sodium and volume dysregulation after apparently normal pregnancy is suggested by abnormal levels of atrial natriuretic peptide, renin and aldosterone. Clin Exp Pharmacol Physiol 1991; 18(5): 269-73.

4. Schrier RW, Briner VA. Peripheral arterial vasodilation hypothesis of sodium and water retention in pregnancy: implications for pathogenesis of preeclampsia-eclampsia. Obstet Gynecol 1991; $77(4): 632-9$.

5. Duvekot JJ, Cheriex EC, Pieters FA, Menheere PP, Peeters LH. Early pregnancy changes in hemodynamics and volume homeostasis are consecutive adjustments triggered by a primary fall in systemic vascular tone. Am J Obstet Gynecol 1993; 169(6): 1382-92.

6. Weiner CP, Thompson LP. Nitric oxide and pregnancy. Semin Perinatol 1997; 21(5): 367-80.

7. Baylis $\mathrm{C}$. Glomerular filtration and volume regulation in gravid animal models. Baillieres Clin Obstet Gynaecol 1994; 8(2): 23564.

8. Khraibi AA. Renal interstitial hydrostatic pressure and sodium excretion in hypertension and pregnancy. J Hypertens Suppl 2002; 20(3): S21-S27.

9. Khraibi AA, Yu T, Tang D. Role of nitric oxide in the natriuretic and diuretic responses in pregnant rats. Am J Physiol Renal Physiol 2003; 285(5): F938-F944.

10. Carbillon L, Uzan M, Uzan S. Pregnancy, vascular tone, and maternal hemodynamics: a crucial adaptation. Obstet Gynecol Surv 2000; 55(9): 574-81.

11. Chapman AB, Abraham WT, Zamudio S, Coffin C, Merouani A, Young D, Johnson A, Osorio F, Goldberg C, Moore LG, Dahms T, Schrier RW. Temporal relationships between hormonal and hemodynamic changes in early human pregnancy. Kidney Int 1998; 54(6): 2056-63.

12. Thornburg KL, Jacobson SL, Giraud GD, Morton MJ. Hemodynamic changes in pregnancy. Semin Perinatol 2000; 24(1): 11-4.

13. Blake MJ, Martin A, Manktelow BN, Armstrong C, Halligan AW, Panerai RB, Potter JF. Changes in baroreceptor sensitivity for heart rate during normotensive pregnancy and the puerperium. Clin Sci (Lond) 2000; 98(3): 259-68.

14. Jensen E, Wood C, Keller-Wood M. The normal increase in adrenal secretion during pregnancy contributes to maternal volume expansion and fetal homeostasis. J Soc Gynecol Investig 2002; 9(6): 362-71.

15. Duvekot JJ, Peeters LL. Renal hemodynamics and volume homeostasis in pregnancy. Obstet Gynecol Surv 1994; 49(12): 830-9.

16. van der Post JA, van Buul BJ, Hart AA, van Heerikhuize JJ, Pesman G, Legros JJ, Steegers EA, Swaab DF, Boer K. Vasopressin and oxytocin levels during normal pregnancy: effects of chronic dietary sodium restriction. J Endocrinol 1997; 152(3): 345-54.

17. Eguchi K, Oguni N, Sawai T, Yonezawa M. Comparison of plasma concentrations of arginine vasopressin (AVP) and atrial natriuretic peptide (ANP) in normal and preeclamptic pregnancies. J Perinat Med 1996; 24(5): 437-43. 
18. Ganzevoort W, Rep A, Bonsel GJ, de Vries JI, Wolf H. Plasma volume and blood pressure regulation in hypertensive pregnancy.J Hypertens 2004; 22(7): 1235-42.

19. Garovic VD, Hayman SR. Hypertension in pregnancy: an emerging risk factor for cardiovascular disease. Nat Clin Pract Nephrol 2007; 3(11): 613-22.

20. Yoder SR, Thornburg LL, Bisognano JD. Hypertension in pregnancy and women of childbearing age. Am J Med 2009; 122(10): 890-5.

21. Podymow T, August P. Update on the use of antihypertensive drugs in pregnancy. Hypertension 2008; 51(4): 960-9.

22. Chobanian AV, Bakris GL, Black HR, Cushman WC, Green LA, Izzo JL, Jr., Jones DW, Materson BJ, Oparil S, Wright JT, Jr., Roccella EJ. The Seventh Report of the Joint National Committee on Prevention, Detection, Evaluation, and Treatment of High Blood Pressure: the JNC 7 report. JAMA 2003; 289(19): 2560-72.

23. Mancia G, De BG, Dominiczak A, Cifkova R, Fagard R, Germano G, Grassi G, Heagerty AM, Kjeldsen SE, Laurent S, Narkiewicz K, Ruilope L, Rynkiewicz A, Schmieder RE, Boudier HA, Zanchetti A. 2007 ESH-ESC Practice Guidelines for the Management of Arterial Hypertension: ESH-ESC Task Force on the Management of Arterial Hypertension. J Hypertens 2007; 25(9): 1751-62.

24. Artal R, Lockwood CJ, Brown HL. Weight gain recommendations in pregnancy and the obesity epidemic. Obstet Gynecol 2010; 115(1): 152-5.

25. Sibai BM, Gordon T, Thom E, Caritis SN, Klebanoff M, McNellis $\mathrm{D}$, Paul RH. Risk factors for preeclampsia in healthy nulliparous women: a prospective multicenter study. The National Institute of Child Health and Human Development Network of MaternalFetal Medicine Units. Am J Obstet Gynecol 1995; 172(2 Pt 1): 642-8.

26. Engel SM, Janevic TM, Stein CR, Savitz DA. Maternal smoking, preeclampsia, and infant health outcomes in New York City, 1995-2003. Am J Epidemiol 2009; 169(1): 33-40.

27. Sibai BM. Caring for women with hypertension in pregnancy. JAMA 2007; 298(13): 1566-8.

28. Khan KS, Wojdyla D, Say L, Gulmezoglu AM, Van Look PF. WHO analysis of causes of maternal death: a systematic review. Lancet 2006; 367(9516): 1066-74.

29. Jonsdottir LS, Arngrimsson R, Geirsson RT, Sigvaldason H, Sigfusson N. Death rates from ischemic heart disease in women with a history of hypertension in pregnancy. Acta Obstet Gynecol Scand 1995; 74(10): 772-6.

30. Arnadottir GA, Geirsson RT, Arngrimsson R, Jonsdottir LS, Olafsson O. Cardiovascular death in women who had hypertension in pregnancy: a case-control study. BJOG 2005; 112(3): 286-92.

31. McDonald SD, Malinowski A, Zhou Q, Yusuf S, Devereaux PJ. Cardiovascular sequelae of preeclampsia/eclampsia: a systematic review and meta-analyses. Am Heart J 2008; 156(5): 918-30.

32. Leeman M. [Arterial hypertension in pregnancy]. Rev Med Brux 2008; 29(4): 340-5.

33. Buemi M, Bolignano D, Barilla A, Nostro L, Crasci E, Campo S, Coppolino G, D'Anna R. Preeclampsia and cardiovascular risk: general characteristics, counseling and follow-up. J Nephrol 2008; 21(5): 663-72.

34. Valensise H, Vasapollo B, Gagliardi G, Novelli GP. Early and late preeclampsia: two different maternal hemodynamic states in the latent phase of the disease. Hypertension 2008; 52(5): 87380.
35. Smith GN, Walker MC, Liu A, Wen SW, Swansburg M, Ramshaw $\mathrm{H}$, White RR, Roddy M, Hladunewich M. A history of preeclampsia identifies women who have underlying cardiovascular risk factors. Am J Obstet Gynecol 2009; 200(1): 58.

36. Poranen AK, Ekblad U, Uotila P, Ahotupa M. Lipid peroxidation and antioxidants in normal and pre-eclamptic pregnancies. Placenta 1996; 17(7): 401-5.

37. Many A, Hubel CA, Fisher SJ, Roberts JM, Zhou Y. Invasive cytotrophoblasts manifest evidence of oxidative stress in preeclampsia. Am J Pathol 2000; 156(1): 321-31.

38. Freeman DJ, McManus F, Brown EA, Cherry L, Norrie J, Ramsay JE, Clark P, Walker ID, Sattar N, Greer IA. Short- and long-term changes in plasma inflammatory markers associated with preeclampsia. Hypertension 2004; 44(5): 708-14.

39. Austgulen R, Lien E, Vince G, Redman CW. Increased maternal plasma levels of soluble adhesion molecules (ICAM-1, VCAM1, E-selectin) in preeclampsia. Eur J Obstet Gynecol Reprod Biol 1997; 71(1): 53-8.

40. Greer IA, Dawes J, Johnston TA, Calder AA. Neutrophil activation is confined to the maternal circulation in pregnancy-induced hypertension. Obstet Gynecol 1991; 78(1): 28-32.

41. Weinstein L. Syndrome of hemolysis, elevated liver enzymes, and low platelet count: a severe consequence of hypertension in pregnancy. Am J Obstet Gynecol 1982; 142(2): 159-67.

42. Egerman RS, Sibai BM. HELLP syndrome. Clin Obstet Gynecol 1999; 42(2): 381-9.

43. Joshi D, James A, Quaglia A, Westbrook RH, Heneghan MA. Liver disease in pregnancy. Lancet 2010; 375(9714): 594-605.

44. Sibai BM. Imitators of severe pre-eclampsia. Semin Perinatol 2009 June;33(3):196-205.

45. Tincani A, Bompane D, Danieli E, Doria A. Pregnancy, lupus and antiphospholipid syndrome (Hughes syndrome). Lupus 2006;15(3): 156-60.

46. Levine JS, Branch DW, Rauch J. The antiphospholipid syndrome. NEngl J Med 2002; 346(10): 752-63.

47. Abalos E, Duley L, Steyn DW, Henderson-Smart DJ. Antihypertensive drug therapy for mild to moderate hypertension during pregnancy. Cochrane Database Syst Rev 2001; (2): CD002252.

48. Gebruik van antihypertensiva tijdens de zwangerschap. www. bcfi.be/folia/2005/F32N01B.cfm. 2005. Ref Type: Internet Communication

49. Bortolus R, Ricci E, Chatenoud L, Parazzini F. Nifedipine administered in pregnancy: effect on the development of children at 18 months. BJOG 2000 June;107(6):792-4.

50. Rubin PC, Butters L, Low RA, Reid JL. Atenolol in the treatment of essential hypertension during pregnancy. Br J Clin Pharmacol 1982; 14(2): 279-81.

51. Cooper WO, Hernandez-Diaz S, Arbogast PG, Dudley JA, Dyer S, Gideon PS, Hall K, Ray WA. Major congenital malformations after first-trimester exposure to ACE inhibitors. N Engl J Med 2006; 354(23): 2443-51.

52. Clapp JF, III, Capeless E. Cardiovascular function before, during, and after the first and subsequent pregnancies. Am J Cardiol 1997; 80(11): 1469-73.

53. website of the U.S. Food and Drug Administration. www.fda. com. 2010. Ref Type: Internet Communication

54. Drugsin Pregnancy and Breastfeeding.www.safefetus.com/.2010. Ref Type: Internet Communication 